\title{
Comparison of Periodontal Status between Pregnant and Nonpregnant Women
}

\author{
Jamile Bigom Taheri, Somayyeh Azimi, Ashok Mathew, Mahdiye Pishgahi
}

\begin{abstract}
Aim: Providing complete oral health care for pregnant women is essential. Purpose of this study was to determine the periodontal diseases in pregnant and nonpregnant women in United Arab Emirates (UAE).
\end{abstract}

Materials and methods: A cross-sectional study was carried out in UAE. The sample consisted of two groups of women resident in UAE were selected, one pregnant (mean age 28 years) and nonpregnant (mean age of 23 years). The questionnaires which include personal information, habit, medical and dental history were distributed among women attending the outpatient clinics of Iranian Hospital Dubai and Fujairah AUST Campus. In periodontal chart debris and calculus score for teeth $\# 16,11,26,46,31,36$ were recorded and simplified oral hygiene index was determined. The periodontal parameters like bleeding on probing and loss of attachment of same teeth were independently checked and recorded.

Results: Based on the findings over the questionnaires that were distributed between two groups of 80 volunteers one pregnant and nonpregnant woman, bleeding on probing and loss of attachment is seen more in pregnant women $(p=0.00)$.

Conclusion: There was a significant difference between the periodontal status between pregnant and nonpregnant women in UAE. Thus, pregnant women are more in danger of periodontal diseases and they need more dental care and preventive dentistry programs.

Keywords: Periodontal disease, Pregnancy, Bleeding on probing, Loss of attachment, Simplified oral hygiene index.

How to cite this article: Taheri JB, Azimi S, Mathew A, Pishgahi M. Comparison of Periodontal Status between Pregnant and Nonpregnant Women. Int J Experiment Dent Sci 2013;2(2):82-85.

\section{Source of support: Nil}

Conflict of interest: None declared

\section{INTRODUCTION}

Periodontium consist of the specialized tissues that surround and support the teeth and preserving them in the upper and lower jaws.

Accumulation of microorganisms and growth on tooth surfaces associated with an immune response against these microorganisms causes periodontitis.

Poor oral hygiene, poor nutrition and underlying medical condition such as diabetes are most etiologic factor for gingivitis. ${ }^{1-5}$

Gingivitis may progresses to periodontitis, with the destruction of the gingival fibers, and cause periodontal pocket.
Some studies indicate that, increase level of ovarian sex hormones in women may also influence gingivitis and periodontal disease. Ethnicity (race) also may play a role. ${ }^{6}$

In addition, any infection during pregnancy is important. It showed that periodontitis in pregnant women increase the risk of preterm labor and low birth weight. ${ }^{7}$ Severity of periodontal problems that exist before pregnancy can during the pregnancy, and the risk of these complications escalates. Because of the significant increase in hormones, particularly estrogen and progesterone, during the second or third trimesters of pregnancy, gums may react differently to bacteria of dental plaque. ${ }^{8}$ This may cause redness, swelling, tenderness or bleeding in the gums. Therefore; clinicians should recommend that women considering pregnancy have a periodontal evaluation and prophylactic treatment. ${ }^{9}$

This study was done to determine of periodontal status between pregnant and nonpregnant women in United Arab Emirates (UAE).

\section{MATERIALS AND METHODS}

A cross-sectional study was carried out among 80 women attending the outpatient clinics of Iranian Hospital Dubai and Fujairah AUST Campus. Two groups of women were selected, one pregnant women with mean age of 27.69 years old and second group nonpregnant women with mean age of 22.61 years old. Different nationalities were examined and all were residence of UAE. Two set of questioners were filled with these groups containing patient information and history followed by periodontal examination.

The questioners include questions about: name, age, nationality, age of marriage, number of children you gave birth, duration between each deliver. It also includes the habits such as drug addiction, smoking and alcohol usage. The third and fourth part of questioners includes medical and dental history of volunteers. Fifth part of questioners includes the periodontal examination charts that were filled during the interviewing. The periodontal status was determined by measuring the following on teeth \#16, $11,26,36,31,46$. We examined debris score, calculus, bleeding on probing and loss of attachment. Periodontal examination is done by periodontal Michigan $\mathrm{O}$ probe with William's markings. 


\section{RESULTS}

Results obtained of bleeding on probing, loss of attachment, simplified oral hygiene index (debris index score + calculus index score, 0-1.2 good, 1.3-3 fair, 3.1-6 poor) for pregnant and nonpregnant women.

Nonpregnant group includes 4 Iranian, 15 from UAE, 9 Pakistani, 2 from KSA, 4 Omani, 8 Indian, 4 Egypt, 9 Palestinian and 9 Iraqi.

Pregnant group includes 16 Iranian, 7 from UAE, 8 Indian, 2 Egypt, 2 Chinese, Syrian, 15 Philippine, 5 from Afghanistan, 1 Pakistani. Bleeding on probing and attachment loss is demonstrated in Graphs 1 and 2.

One-way ANOVA test showed that difference between pregnant and nonpregnant women in BOP and attachment loss was significant $(\mathrm{p}=0.00)$.

Simplified oral hygiene index in pregnant and nonpregnant is demonstrated in Graphs 3 and 4.

One-way ANOVA test showed that difference between pregnant and nonpregnant was significant $(p=0.00)$.

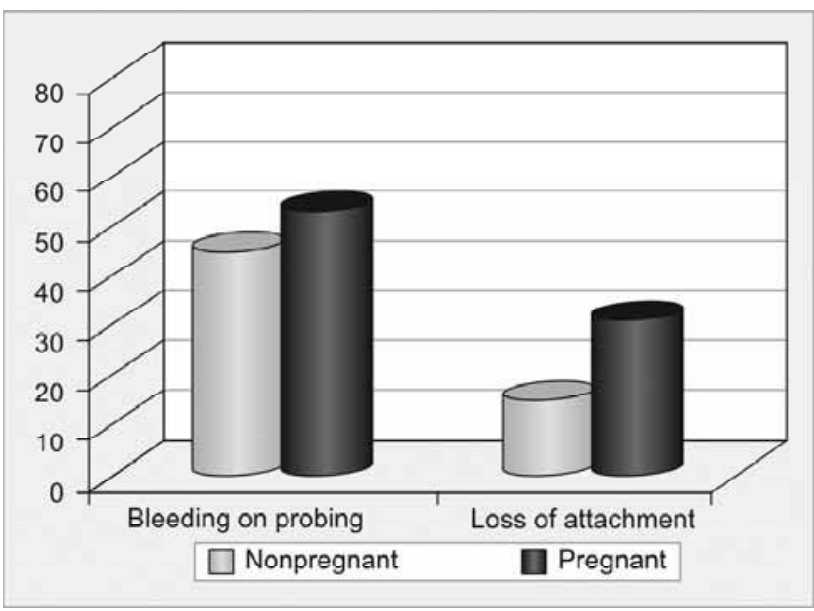

Graph 1: Bleeding on probing and attachment loss in pregnant and nonpregnant groups

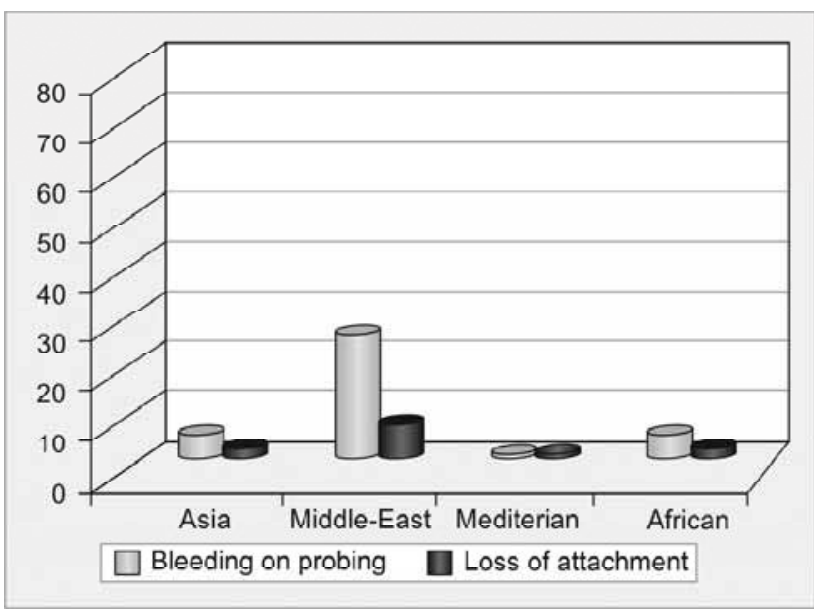

Graph 2: Bleeding on probing and attachment loss in pregnant and nonpregnant considering ethnic group

\section{DISCUSSION}

Based on the findings over the questionnaires that were distributed between two groups of 80 volunteers one pregnant and nonpregnant woman, the outcome was that bleeding on probing and loss of attachment and simplified oral hygiene index is seen more in pregnant women.

Periodontal status is a crucial factor for pregnant women to cause low birth weight. This issue has been investigated by researchers however this matter has not yet reached to define many answers and still many controversies are surrounding it. Some researchers agree on whether the acceptance of periodontitis significant in pregnant causes preterm babies while others are not in agreement of this result. ${ }^{10}$

Results of this study are in agreement with Hashim ${ }^{11}$ some researchers which agreed only in result by evaluating different clinical parameters used in this research were the Silness and Loe plaque index, Loe and Silness gingival

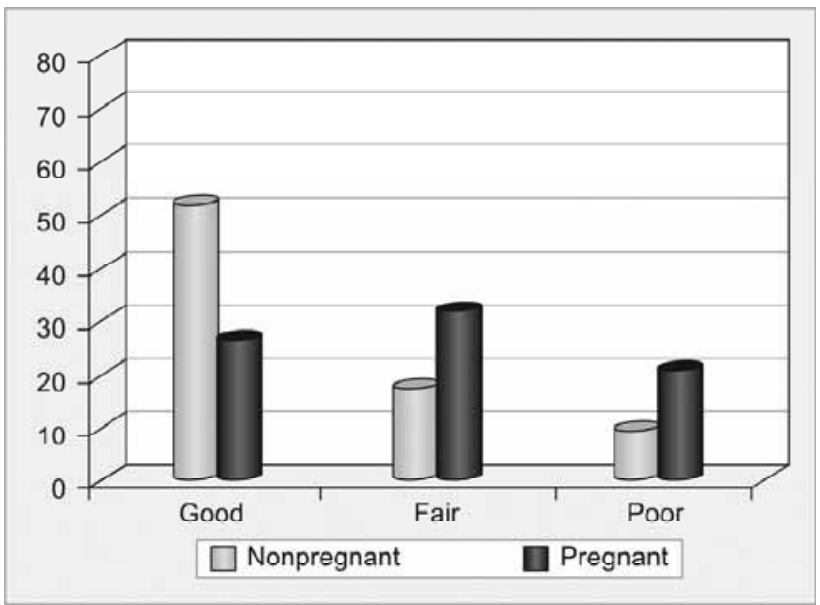

Graph 3: Simplified oral hygiene index in pregnant and nonpregnant groups

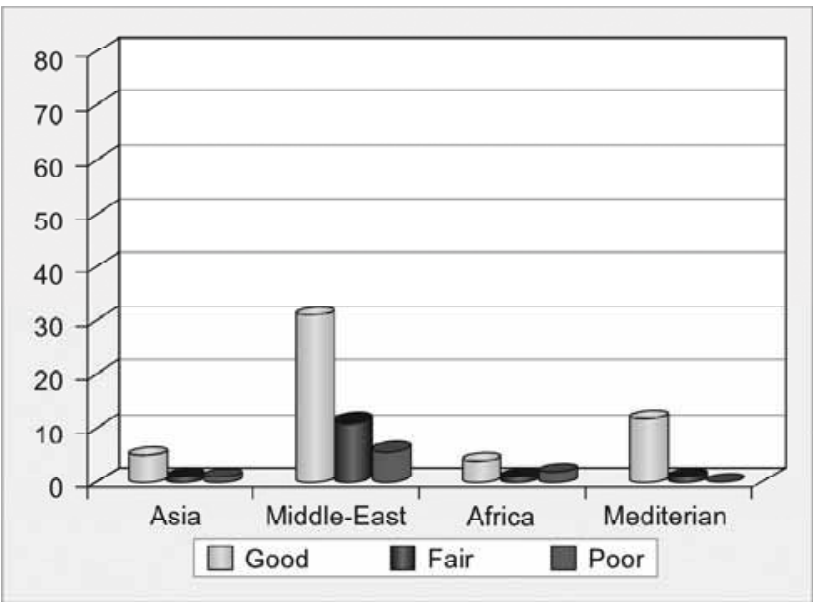

Graph 4: Simplified oral hygiene index in pregnant and nonpregnant considering ethnic group 
index (GI), probing pocket depth (PPD) but in loss of attachment it shows different outcomes than our results. ${ }^{12-14}$

However, Vergnes and Sixou et a $1^{15}$ were unclear about the relation between periodontal disease and the effect on babies and Miyazaki $\mathrm{H} \mathrm{et} \mathrm{al}{ }^{16}$ were not in agreement of this relation.

For better results and analysis, we ideally should consider in increasing the sample size. To find out the exact influencing factors in periodontitis in pregnant women, we have to follow-up subjects at least 3 months postdelivery and re-evaluate the parameters used in this study again on the same subjects.

\section{CONCLUSION}

Statistical analysis suggested that bleeding on probing; loss of attachment and simplified oral hygiene status (SOHI) index is significant in pregnant women compared to nonpregnant women. Therefore, clinicians should recommend that women considering pregnancy have a periodontal evaluation and prophylactic treatment. Oral health guidelines for pregnant women assist them in maintaining healthy teeth and gums during their pregnancy and into the early stages of motherhood. ${ }^{17}$

\section{ACKNOWLEDGMENT}

This article was based on an undergraduate thesis by Mahdiye Pishgahi which was successfully complete under the supervision of Dr Mathew and Dr Taheri along with the close co-operation of Ajman University of Science and Technology and Dental School of Shahid Beheshti University of Medical Sciences.

\section{REFERENCES}

1. Crich A. Blastomycosis of the gingiva and jaw. Can Med Assoc J 1932;26(6):662-665.

2. Urzúa B, Hermosilla G, Gamonal J, Morales-Bozo I, Canals M, Barahona S, Cóccola C, Cifuentes V. Yeast diversity in the oral microbiota of subjects with periodontitis: Candida albicans and Candida dubliniensis colonize the periodontal Pockets. Med Mycol 2008;46(8):783-793.

3. Matsuo T, Nakagawa H, Matsuo N. Endogenous Aspergillus endophthalmitis associated with periodontitis. Ophthalmologica 1995;209(2):109-111.

4. Migliari DA, Sugaya NN, Mimura MA, Cucé LC. Periodontal aspects of the juvenile form of paracoccidioidomycosis. Rev Inst Med Trop Sao Paulo 1998 Jan-Feb;40(1):15-18.

5. Lalla E, Cheng B, Lal S, Kaplan S, Softness B, Greenberg E, Goland RS, Lamster IB. Diabetes mellitus promotes periodontal destruction in children. J Clin Periodontol 2007 Apr;34(4): 294-298.
6. Zachariasen RD. The effect of elevated ovarian hormones on periodontal health: oral contraceptives and pregnancy. Womens Health 1993;20(2):21-30.

7. Socransky SS, Haffajee AD, Cugini MA, Smith C, Kent RL Jr. Microbial complexes in subgingival plaque. J Clin Periodontol 1998;25:134-144.

8. Zachariasen R. Ovarian hormones and oral health: pregnancy gingivitis. Compend Cont Educ Dent 1989;10-508-512.

9. Sant'Ana AC, Campos MR, Passanezi SC, Rezende ML, Greghi SL, Passanezi E. Periodontal treatment during pregnancy decreases the rate of adverse pregnancy outcome: a controlled clinical trial. J Appl Oral Sci 2011 Apr;19(2):130-136.

10. McCann AL, Bonci L. Maintaining women's oral health. Dent Clin North Am 2001;45:571-601.

11. Hashim R. Self-reported oral health, oral hygiene habits and dental service utilization among pregnant women in United Arab Emirates. Int J Dent Hyg 2012 May;10(2):142-146.

12. Taani DQ, Habashneh R, Hammad MM, Batieha A. The periodontal status of pregnant women and its relationship with sociodemographic and clinical variables. J Oral Rehabil 2003 Apr;30(4):440-445.

13. Rai B. Periodontal disease and preterm delivery of low birth weight infants: a small survey. Adv Med Dent Sci 2008;2(3): 84-85.

14. Radnai M, Gorzó I, Nagy E, UrbánE, Novák T, Pál A. A possible association between preterm birth and early periodontitis. Pilot study. J Clin Periodontol 2004;31;736-741.

15. Vergnes JN, Sixou M. Preterm low birth weight and maternal periodontal status: a meta-analysis. Am J Obstet Gynecol 2007; 196(2):135.e1-7.

16. Miyazaki H, Yamashita Y, Shirahama R, Goto-Kimura K, Shimada N, Sogame A, Takehara T. Periodontal condition of pregnant women assessed by CPITN. J Clin Periodontol 1991;18:751-754.

17. Saini R, Saini S, Saini SR. Periodontitis: A risk for delivery of premature labor and low birth weight infants. J Nat Sc Biol Med 2011;2:50-52.

\section{ABOUT THE AUTHORS Jamile Bigom Taheri}

Professor, Department of Oral Medicine, Shahid Beheshti University of Medical Sciences, Tehran, Iran

\section{Somayyeh Azimi (Corresponding Author)}

Assistant Professor, Department of Oral Medicine, Shahid Beheshti University of Medical Sciences, Tehran, Iran, e-mail: somayyeh_azimi@yahoo.com

\section{Ashok Mathew}

Assistant Professor, Department of Oral Medicine, Ajman University of Science and Technology, Ajman, UAE

\section{Mahdiye Pishgahi}

Student, Department of Oral Medicine, Shahid Beheshti University of Sciences and Technology, Tehran, Iran 


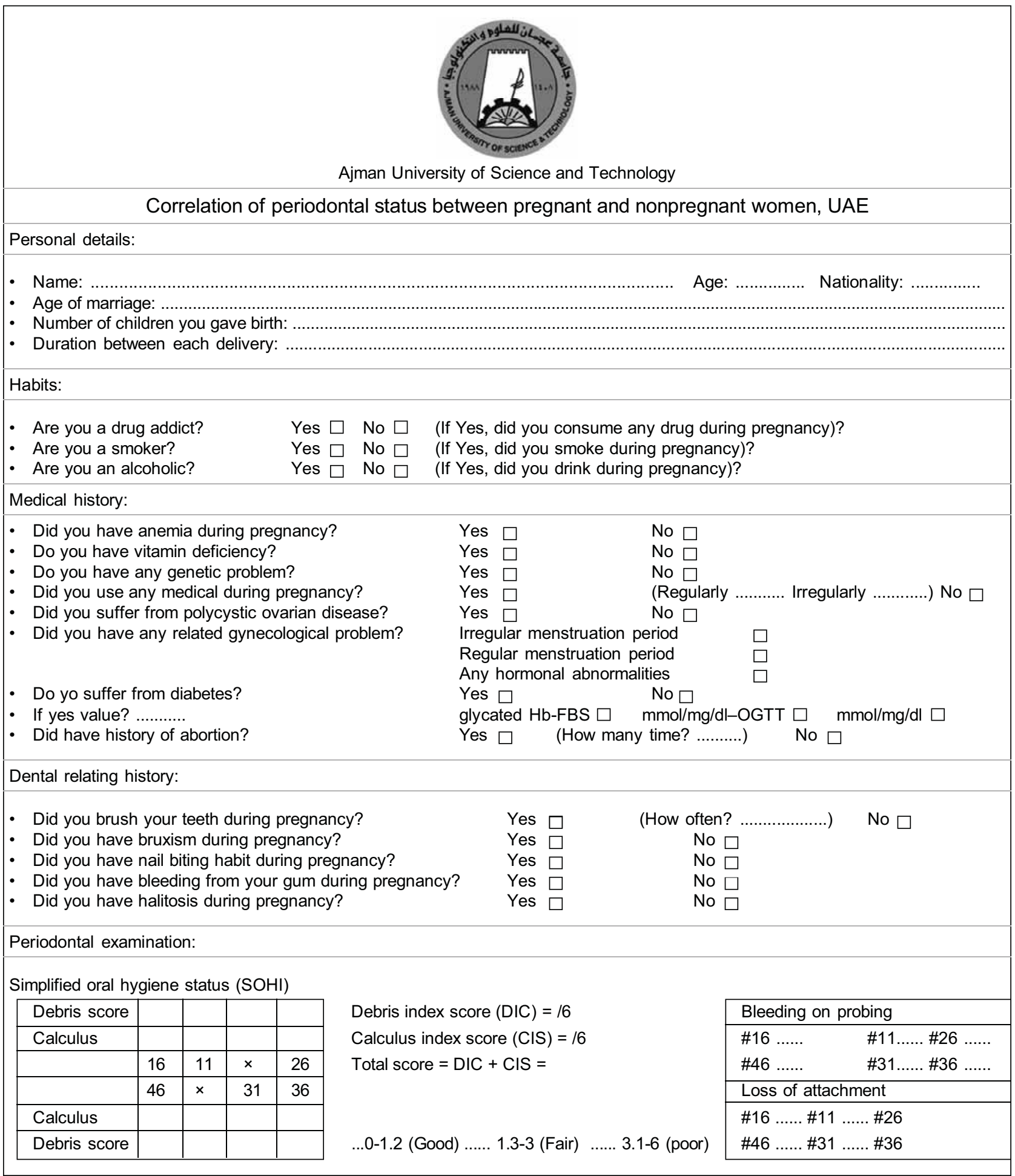

